\title{
The Fundamentals and Recent Applications of Micellar System Extraction for Nanoparticles and Bioactive Molecules: A Review
}

\author{
Ebaa Adnan Azooz ${ }^{1}$, Rana Kadhim Ridha ${ }^{2}$, Hawraa Ali Abdulridha ${ }^{1}$ \\ ${ }^{1}$ The Gifted Students' School in Al-Najaf, Ministry of Education, Iraq. \\ ${ }^{2}$ Department of Dairy Science and Technology, College of Food Sciences, Al-Qasim Green University, Iraq. \\ C Corresponding authors. E-mail: ebaaadnan.ed12@uokufa.edu.iq; ranakhadim@fosci.uoqasim.edu.iq; hawraa1975@yahoo.com
}

Received: May 21, 2021; Accepted: Aug. 3, 2021; Published: Sep. 6, 2021

Citation: Ebaa Adnan Azooz, Rana Kadhim Ridha, and Hawraa Ali Abdulridha, The Fundamentals and Recent Applications of Micellar System Extraction for Nanoparticles and Bioactive Molecules: A Review. Nano Biomed. Eng., 202I, 13(3): 264-278. DOI: 10.5101/nbe.v13i3.p264-278.

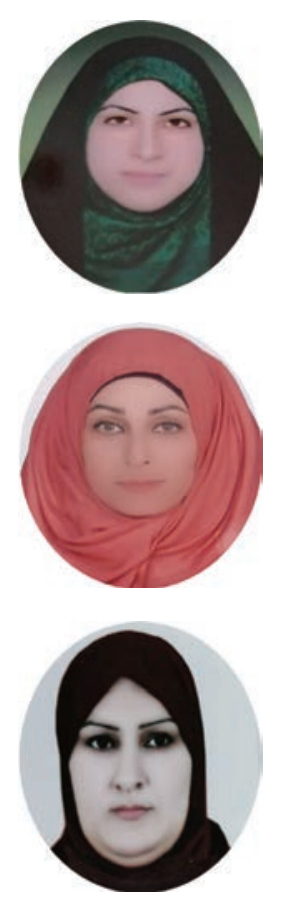

Ebaa Adnan Azooz, Ph.D. in Analytical Chemistry, University of Kufa, Iraq. Her research interests include separation methods, solvent extraction, cloud point extraction, bio-nanomaterials, and environmental studies. She is a lecturer at The Gifted Students' School in Najaf, Ministry of Education, Iraq.

Dr. Azooz works as an editor and a reviewer for many scientific journals. She has many published papers in Scopus and Clarivate journals.

Rana Kadhim Ridha, M. Sc. in Analytical Chemistry, University of Kufa, Iraq. Her research interests include nanomaterial separation methods, solvent extraction, and element determination in food. She is a lecturer in the Department of Dairy Science and Technology, College of Al-Qasim Green University, Iraq. Mrs. Ridha has many published papers in Scopus journals.

Hawraa Ali Abdulridha, Ph. D. in Molecular and Theoretical Physics, University of Baghdad, Iraq. Her research interests include the study of structural properties, electronic properties, graphene sheets, and nanotechnology.She is a lecturer at The Gifted Students'School in Najaf, Ministry of Education, Iraq.She has many published papers in Scopus journals.

\begin{abstract}
The basics and uses of the micellar system extraction technique (MSE) for extracting and preconcentrating nanoparticles and bioactive compounds (medicines and vitamins) are covered in this review. Hence, the influential factors of the MSE and applications are offered. The MSE, like any separation process, extracts the analytes in a small phase from the solution to improve analysis quality and remove sample background interference. The MSE has several advantages over other preconcentration and separation methods, such as speed, cheapness, security, selectivity, and safety. The use of toxic organic solvents is reduced or ignored, and the process is economical and environmentally friendly. In the latest works of literature, three different procedures use to extract nanomaterials. So bioactive molecules were separated by two methods with MSE, and this review also provided newly-developed MSE.
\end{abstract}

Keywords: Nanoparticles, Cloud point extraction, Vitamins, Medicines, Micelle mediate extraction 


\section{Introduction}

In general, MSE stands for modified extraction methods that use a surfactant instead of an organic solvent. Micelle Mediate Extraction (MME) or Cloud Point Extraction (CPE) are two terms for the MSE. It depends on the formation of the micelle layer (ML) in aqueous solutions, whereby the polar heads on the micelle's exterior and non-polar tails orient themselves into the interior [1-4]. ML is formed by dissolving the surfactants in an aqueous medium, but in an organic medium, reverse micelles (RM) are formed [5-7]. It is possible to describe the micellar system as a thin layer circle consisting of an inward organic pool core and aqueous solutions centered on external surfactant molecules [8-10]. The micellar system (MS) is described by the formation of a hydrophobic layer in an aqueous solution that is controlled by a surfactant [11]. The arrangement of the micelles is shown as an "oil-in-water" structure [12-14]. Micelle formation increases the affinity of analytic species that are dissolved in the organic phase, while the RM is used to attract analytes that are dissolved in the water. The affinity of the specified analytes for the micelle or RM is determined by the micro-environment in which the analytes are dissolved [15]. Figs. 1 and 2 depict the

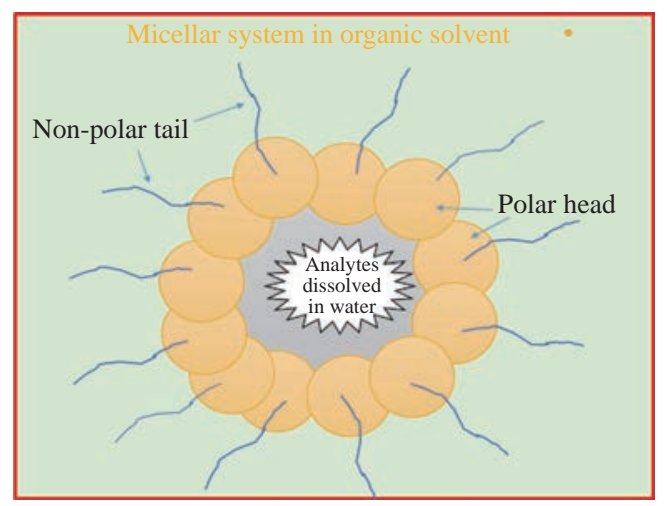

Fig. 1 The arrangement of the micellar system (MS).

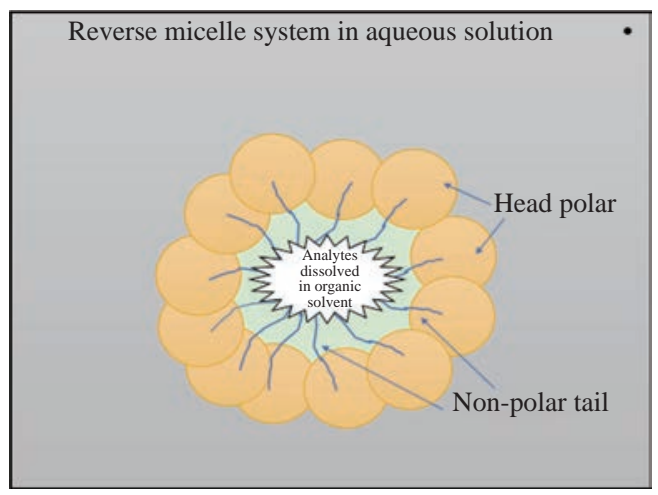

Fig. 2 The arrangement of the reverse micellar system (RM). various configurations of the MS and RM.

The first time this technique was applied in 1976 for preconcentration and determination of $\mathrm{Ni}(\mathrm{II})$ used 1-(2-Thiazolylazo)-2-naphthol (TAN) and Triton X-100 as micellar mediators [16]. Ever since, the technique is still applied in the extraction of analytes (metals, vitamins, organic materials, nanoparticles and other [17].

MSE has been widely studied recently as an environmentally fast, selective, accurate, and green approach to preconcentration and separation of several solutes, providing many other benefits over previous solvent extraction. The MSE is dependent on micelle mediating agents' ability to form ML in water when heated above a certain temperature, known as the critical temperature (CT) [18-20].

Nanomaterials have many forms-for example, cylindrical, tubular, spherical, and platform-form morphology, as they are designed according to the requirements for special applications. The enormous variety of forms and chemical composition of nanomaterials, as well as the possibility of particle surface alterations, make this a vital and active topic of research. Nanomaterials are useful in biological and pharmaceutical applications because they have a special size, shape, and surface area. Also, products made by physical or chemical methods consume a lot of energy and produce toxic waste that is hazardous to the environment. In recent years, using a green strategy to synthesize nanomaterials has proven to be quite beneficial because it is an environmentally friendly, cost-effective, and quick process [144-146]. Several MSE papers are discussed in this review. The principles and factors that affected the MSE will be reported in the next part. In addition, the description of the methods used by scientists for extraction of both nanoparticles and bioactive molecules and the essential parameters used in the research are outlined in the next paragraph.

\section{MSE General Principles}

The MSE is based on the ML synthesis when an aqueous medium containing a micelle mediate reagent (MMR) and heating above CT. The low volume of surfactant occurs as monomers in the aqueous medium. The molecules aggregate to form micelles when MMR concentration exceeds critical micellar concentration (CMC) and heating over CT. To avoid interaction with 
water, the tails (non-polar) connect to the interior layer of a standard micelle. The polar heads, on the other hand, observe water molecules in the exterior layer. [21-24]. Salting-out is a phenomenon that produces ML after the addition of a natural salt such as $\mathrm{NaNO}_{3}$ at a specific temperature $\left(25^{\circ} \mathrm{C}\right)$ based on the surfactant. The process separation can be done and improved by the centrifugal tube after ML formation [25]. The under layer already contains hydrophobic species and most of the MMR. The aqueous layer (AL) includes any components or metals that cannot be aggregated into ML. Heating helps to aggregate micelles with fewer repulsions and form a separation phase by dehydration of polar groups of the micelle mediate reagent [26,27]. This procedure was explained in Fig. 3.

\section{Analyte Influence Factors}

Hydrophobicity is an essential condition for the incorporation of analytes into the ML. The analytes should, when separated by MSE, be either hydrophobic or convertible to hydrophobic particles [14]. Therefore, it is difficult to separate some hydrophilic molecules directly from MSE. Metal ions, for example, should be chelated with a suitable reagent before MSE to convert them to hydrophobic species [7,8]. However, organic molecules (proteins, phenols, azo compounds, drugs and others) may be separated without chelation [28-30].

\section{The pH effect}

The medium $\mathrm{pH}$ is a major factor that controls MSE, in particular for ionic molecules like metals, amines, amino acids, and azo compounds. Every MSE approach has an optimal $\mathrm{pH}$ range for extracting analytes quantitatively. In this range, the accidentally discharged form of the solutes exists and can interact with the micelles $[14,20]$. The $\mathrm{pH}$ can improve the extraction efficiency of the extracted species, which has a significant impact on the extraction of metal ions by MSE [30]. By using alizarin red $\mathrm{S}$ as well as cetyltrimethylammonium bromide (CTAB) with Triton $\mathrm{X}-114$, the $\mathrm{pH}$ medium is essential to the separation between Sc(III) and several lanthanides of clay samples, at room temperature in the presence of KI (0.1 M). $\mathrm{Sc}(\mathrm{III})$ is separated above $\mathrm{pH}=4$ from the other lanthanides [31]. In another research, the extraction of iron and mercury in food samples is excellent at $\mathrm{pH} 9$ by using an azo compound [methyl phenyl thiazolylazo azo]-3-methyl-4-methoxy-2-naphthol (MPTAN) and tritonX-100 as a surfactant [32]. Due to the presence of 4-(pylorophenyl)-1-(pyridine-2-yl) thiosemicarbazide (HCPTS) in the presence of TritonX-114 in the form of $\mathrm{Pt}(\mathrm{IV})$ as a steady hydrophobic species with thiosemicarbazide derivation, it was possible to separate $\mathrm{Pt}(\mathrm{II})$ from $\mathrm{Pt}(\mathrm{IV})$ at $\mathrm{pH}$ 7. This method has been established to analyze Pt in highly accurate blood plasma and urine [33]. Many studies with different factors affecting extraction were described in Table 1. Because protonated phenols are hydrophobic and can be extracted into ML at a lower $\mathrm{pH}$, the extraction of phenols requires a lower $\mathrm{pH}$ value in principle. The optimal pH value is chosen at 5 [34]. To separate parabens from water samples, the basic $\mathrm{pH}$ value is used. Since the hydroxyl group has been fully deprotonated and given full percentage recovery at $\mathrm{pH}$ 9 , parabens appear in a more negatively charged form. As a result, when parabens are deprotonated, hydrogen bonding, electrostatic attraction, and deprotonated interaction can be the most important interactions between positively charged $\beta C D-I L$ and parabens [38]. The $\mathrm{pH}$ value depends on the structure of the analytes, extraction species, ligands, and MMR.

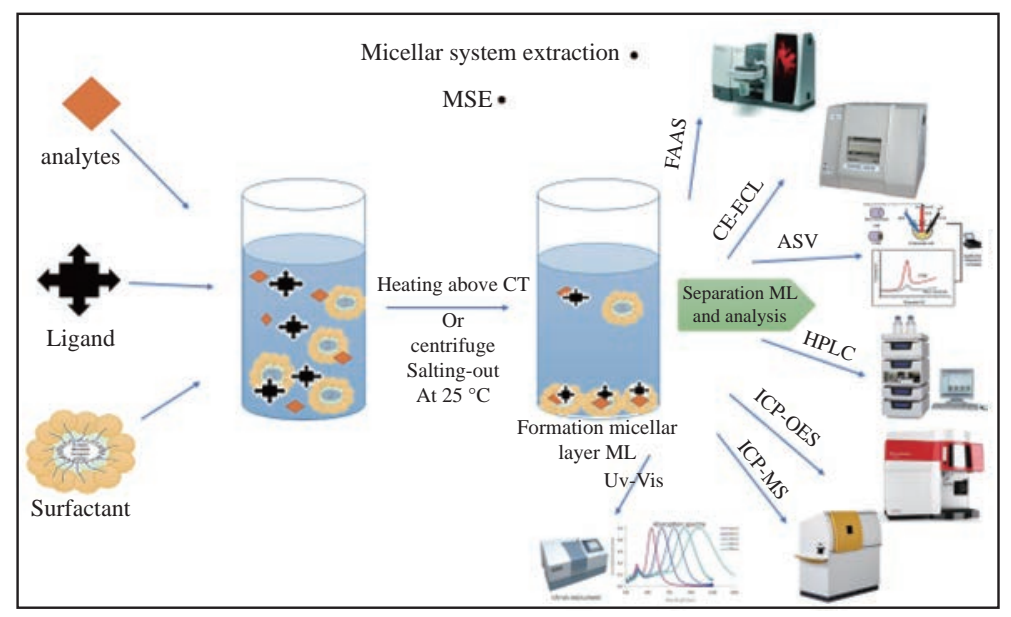

Fig. 3 MSE general procedure. 
Table 1 Effects of some factors on MSE

\begin{tabular}{|c|c|c|c|c|c|c|}
\hline Analytes & Surfactant & $\mathrm{pH}$ & $\mathrm{T}\left({ }^{\circ} \mathrm{C}\right)$ & Salts/Ligands & Applications & Ref. \\
\hline Auxins & Triton X-114 & Acidic $\geq 5$ & -- & (AEMP) & Plants & 34 \\
\hline $\operatorname{Ag}(I)$ & Triton X-100 & -- & 90 & $\mathrm{KNO}_{3} /$ vitamin $\mathrm{C}$ & Water and soil & 39 \\
\hline $\mathrm{Cr}(\mathrm{III}) \mathrm{Cr}(\mathrm{VI})$ & Triton X-114 & 5.5 & 40 & -/TAN & Sediment & 36 \\
\hline $\mathrm{Al}(\mathrm{III})$ & PONPE 5.0 & 5.8 & 70 & 8-hydroxyquinoline & Water & 37 \\
\hline Paraben & DC193C & 9 & 30 & $-/ \beta C D$ & Water & 38 \\
\hline $\mathrm{Cu}(\mathrm{II}) \mathrm{Zn}(\mathrm{II})$ & Triton X-114 & 6.5 & 45 & $\mathrm{NaCl} / \mathrm{DBDP}$ & River and waste water, blood, and soil & 45 \\
\hline $\operatorname{Mg}(\mathrm{II})$ & Triton X-100 & Basic & 90 & -/Rhodamine-B & Food and water & 46 \\
\hline $\mathrm{Mn}(\mathrm{VII})$ & Triton X-100 & Acidic & 90 & -/PANN & Food and water & 13 \\
\hline $\mathrm{Pb}(\mathrm{II})$ & Triton X-114 and CTAB & 1 & 23 & Crown ether & Biological & 47 \\
\hline $\mathrm{U}(\mathrm{VI})$ & Triton X-114 and CTAB & 3.5 & 20 & $\mathrm{KI}+\mathrm{KNO}_{3} / \mathrm{H}_{2} \mathrm{DEH}[\mathrm{MDP}]$ & Water & 49 \\
\hline $\mathrm{Cu}(\mathrm{II})$ & Triton X-100 & 2 & $15-30$ & $\mathrm{Na}_{2} \mathrm{SO}_{4} /$ dithiazone & Water & 55 \\
\hline
\end{tabular}

Note: 2-aminoethyl)-1-methylpyrrolidine (AEMP), 1-(2-thiazolylazo)-2-naphthol (TAN), $\beta$-cyclodextrin ( $\beta C D)$, N, N'-diacetyl-4-bromo-2,6di(aminomethyl) phenol (DBDP), 3-[(2-Pyridyl azo)]-1-nitroso-2-naphthol (PANN), 4',4"(5")-di-tert-butyldicyclohexano-18-crown-6 (Crown ether), P, P-di(2-ethylhexyl) methane di phosphonic acid) (H2DEH[MDP]).

\section{Surfactants}

In MSE, the surfactant is a necessary chemical that forms a micellar layer that catches the substance to be extracted. The amphiphilic substances must have a charged or hydrophilic head and a hydrophobic tail. The capacity of MMR solutions to enhance hydrophobic species solubility (e.g., medicines, azo compounds, optical samples, antioxidants, stabilizers) in an aqueous solution is one of their most important qualities [5-7]. And that is according to the capacity of surfactant molecules to aggregate over a fixed concentration related to the CMC and to create nanosized aggregates, especially micelles. Micelles with hydrophobic cavities are used as Nano-containers to increase the solubility of organic substances in aqueous media. Hydrotropic modifications that alter the aggregation and behavior of micellar structures, such as their solubility features, may be used to achieve an additional effect [39-41]. According to the structure of the polar group, MMRs are categorized into four types (non-ionic, cationic, anionic, and zewitter ionic). Scheme 1 is a graphical summary of the various types of surfactants and examples of their main properties. On-ionic surfactants are water-soluble and have a weak ionization.

Nonionic surfactants of the Triton ${ }^{\circledR} \mathrm{X}$ series are a subset of specific nonionic surfactants. The functional group of these compounds is Polyoxyethylenes, which has a general formula of $\mathrm{RO}\left(\mathrm{CH}_{2} \mathrm{CH}_{2} \mathrm{O}\right)_{\mathrm{n}} \mathrm{H}$. This group can't function as acids in water because the hydrogen atom isn't ionizable. The polyoxyethylene-7.5-octyl phenoxy ether (Triton X-114) and polyoxyethylene9.5-octyl phenoxy ether (Triton X-100) are used widely in MSE. Also, non-ionic surfactants are used alone or mixed with ionic surfactants in MSE [43]. Because of their lipophilic composition, they are very stable and are unaffected by the presence of salts, bases, acids, or dissolving agents for both organic and aqueous solutions [9-11]. In the MSE, the amount of surfactant is also the most important factor. The ML is only

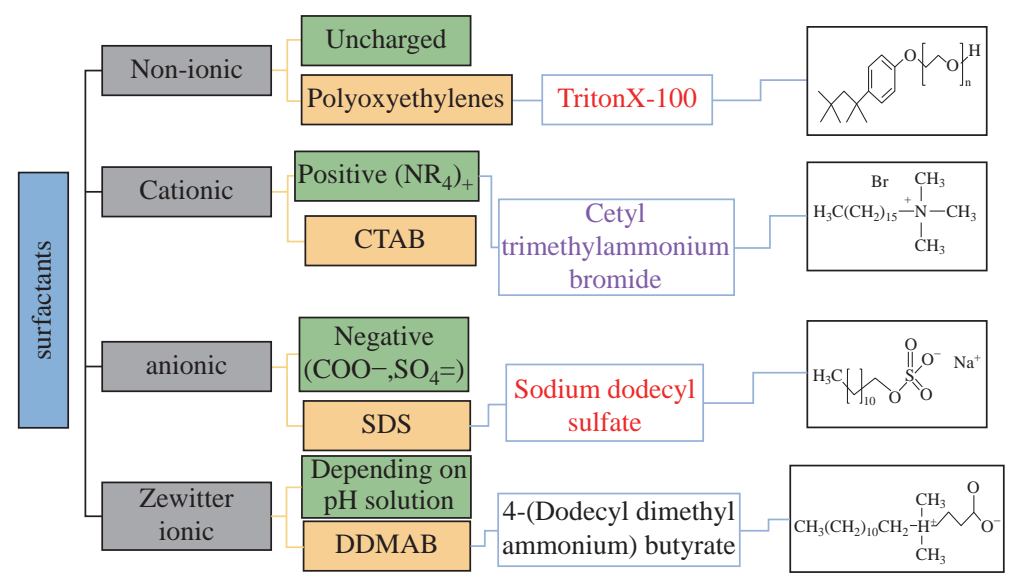

Scheme 1 Classification of Surfactants and Examples. 
available in a very limited concentration range. Due to a decrease in the enhancement factor, increasing surfactant concentration reduces extraction efficiency $[44,46]$. In some cases, a mixture of some categories of surfactants is used to enhance MSE performance. Triton X-114 and Cetyl trimethylammonium bromide (CTAB) were used in the micellar system to separate $\mathrm{Pb}$ in biological tests. This addition causes the creation of mixed surfactants which enhances the solubility of the micellar solution in water. Also, rising the CTAB amount would help raise the CT of the method. The charges on the micelle's surface will cause electrostatic repulsive forces between micelles, which will prevent micelle formation at lower temperatures [48]. CTAB was added to TritonX-114 to reduce the $\mathrm{CT}$ of the device from $28-20^{\circ} \mathrm{C}$ using this concept for uranium extraction in an acidic medium [49]. In the Table 1 report, these ideas were employed in several investigations.

\section{Salting-out effect}

Salting-out is a phenomenon used to improve extraction efficiency. In an aqueous solution, additional salts increase ionic force and break the hydration shell of metal ions. The structure and concentration of additional salts have a significant impact on MSE [6,7]. In the absence of a significant quantity of electrolyte, the non-electrolyte becomes less soluble, depending on the salting-out procedure. Increasing non-polar interactions among micelles by adding salt to the micellar medium resulted in increased dehydration between them. Turbidity is created when the volume of surfactant crosses the CMC, and the ML is formed [50]. Using the salting-out process in MSE may often eliminate the heating step, reducing the time required for the extraction procedure [5,8]. For extraction, metal ions were added to $\mathrm{NaCl}$ at a lower required temperature to form ML of Triton X-114 and apply this procedure to biological samples [45]. With the addition of $1.5 \mathrm{M}$ salt to the MSE process, the temperature drops to $25{ }^{\circ} \mathrm{C}$, resulting in better separation and the elimination of the need for tools such as a sonicator to increase the temperature. $\mathrm{Na}_{2} \mathrm{SO}_{4}, \mathrm{KOH}, \mathrm{NaOH}, \mathrm{K}_{3} \mathrm{PO}_{4}$, and $\mathrm{KNO}_{3}$ are common salts used for MSE and phase separation [8]. Sometimes, the observation is that salts with a higher ionic force form a greater separation. For example, $\mathrm{SO}_{4}{ }^{2-}$ ions provide a good separation as they have a higher affinity for water compared to water-water affinity. On the other hand, the salting-out result of $\mathrm{Na}^{+}$is much greater than that of other tested cations, which also achieve a high Gibbs free energy of hydration [51]. The parameters are reported in Table 1. Salt has a critical role in extraction with the application of a surfactant as it increases the separation. Despite this, higher salt concentrations reduce the efficiency of surfactant recovery and allow the surfactant to be more soluble in water due to a decrease in extraction efficiency. In many of the studies conducted, the amount of salt should be between (1.0-2.0) M. Smaller amounts do not allow the surfactant to fully carry out the separation, while greater amounts of many salts, like $\mathrm{Na}_{2} \mathrm{SO}_{4}$, form a precipitate that inhibits the separation and also the extraction [52]. Researchers chose $\mathrm{KNO}_{3}$ as salt for extraction and determination of $\mathrm{Cu}(\mathrm{II})$ in real samples because it produces excellent results and has a low detection limit (D.L.) [7].

\section{Temperature and time effect}

Temperature is one of the MSE parameters, and the temperature effect is throughout the entire extraction method of the micelles aggregation. Higher heat supports the backward extraction method. Besides that, high temperatures can trigger the denaturation of biomolecules, especially enzymes and proteins, which could be damaged just above the ideal temperature [53]. At a temperature higher than CT, the ML is disturbed by dehydration of the micelles and the transfer of biomolecules towards the surfactant happens more easily, leading to higher extraction and recovery [54]. Even then, the temperature must be closely regulated because the high temperature induces instability in MSE and reduces the recovery rate [13]. In certain situations, in the presence of a large amount of salt (salting-out phenomenon), separation could take place at room temperature [55]. Even with preconcentration, the best heating time and temperature are required to achieve a simple and effective ML.

Heating time response is a kinetic function while the temperature is a thermodynamic function [11]. The aggregation of micelles is specifically applied by the behavior of the employed surfactant. The optimum temperature obtained for $\mathrm{Hg}$ (II) extraction was $35^{\circ} \mathrm{C}$, and a heating time of 5 minutes in a water bath was sufficient to achieve quantitative extraction [56]. In a similar study, 10 minutes at $25^{\circ} \mathrm{C}$ was sufficient to form an excellent separation and obtain a quantitative analysis. This time, there is no improvement in separation [57]. In some cases, it displays instability of separation with the interference of salt in the MSE process. Meanwhile, extraction times shorter than 5 minutes are not recommended because ML must be incomplete and only begin to occur. So, even for 
this process, the ideal time would be in the range of (5-10) min. A temperature exceeding $90{ }^{\circ} \mathrm{C}$ induces evaporation of the solution, which results in the loss of the desired sample. Low temperatures (below $20{ }^{\circ} \mathrm{C}$ ) limit the separation because the analytes are immobile at low temperatures. Mice couldnıt work well either at the time [11-14].

\section{Applications of MSE in Literature}

Preconcentration and separation procedures with MSE are widely applied to separate and extract different analytes from samples [18]. It gets major attention since it is the simplest, rapid, and most flexible procedure for preconcentration and hydrophobic complex extraction from the aqueous environment [13]. Depending on its large recovery and concentration factor, MSE is described as a real alternative to preconcentrate methods [58]. It is known as the green method due to the use of media diluted extractor solutions as a surfactant that is relatively cheap, leading to less output of substances [59]. It reduces the use of toxic chemicals, which is beneficial to both human health and the environment. MSE is now used at room temperature and combined with various devices (explained in Fig. 3) to separate a wide range of species, including nanoparticles, biomolecules, organic materials, and metal ions.

\section{Separation nanoparticles by MSE}

Nanotechnology has sparked interest in a variety of sectors recently, including chemistry, medicine [60], biotechnology [61], and the food industry [62], among others, due to the unique physical and mechanical properties of nanoparticles compared to bulk and microscale materials. In this part of the review, the applications of important material, nanoparticles (NPs) are used in many industries and applications because they have a major function in our lives [63]. Part of it is released into the environment as a result of its increased usage, causing some damage. Toxicity is determined by the dosage as well as the route of ingestion [64]. Table 2 summarizes the possible

Table 2 Potential health risks of selected nanomaterials

\begin{tabular}{ccc}
\hline Nanoparticles & Medical effects & Ref. \\
\hline Silica NPs & DNA damage; liver disease & 78 \\
Titania NPs & Oxidative stress & 79 \\
CNTs & Geno damage, lung lesions and neurotoxicity & 80 \\
Ag NPs & Circulative, gastrointestinal, and central & 81 \\
Au NPs & nervous hepatic systems effects & 82 \\
\hline
\end{tabular}

medical risks associated with some NPs.

Researchers in chemistry have difficulty determining NPs. In actual samples, the concentrations of NPs are very small and below the D.L. for most analytical instruments. First, before the analysis, a process of preconcentration is necessary. The commonly used NP preconcentration methods, i.e. ultra-centrifuge and ultra-filtration, change the physical character of NPs, such as density polarization, aggregation, and particle diameter variations $[65,66]$. Extraction methods are used to separate carbon NPs very well [67]. NPs were widely used in the MSE at the time in three procedures:

(1) MSE was used mainly for preconcentration of NPs from real samples [68].

(2) NPs can act as a catalyst phase to support specific species in the surfactant-rich phase.

(3) NPs have a special chemical composition; they are used as optical sensor material. This section will go through each of these directions. Scheme 2 explains these methods. In the first role, discussion of preconcentration and extraction of NPs by using MSE.

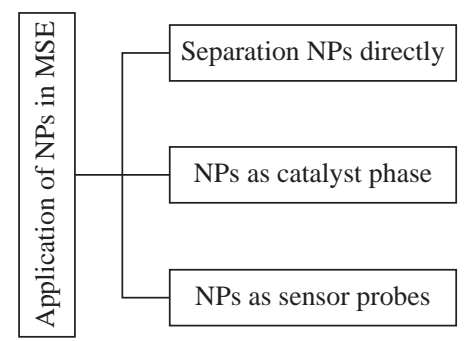

Scheme 2 Three approaches using NPs in MSE.

The use of silver nanoparticles (AgNPs) as antibacterial agents in the industry has resulted in an increase in their prevalence in the environment [105]. AgNPs were exclusively extracted from biological water tests without affecting their shapes and sizes by MSE with Triton X-114. In the presence of salts such as $\mathrm{NaNO}_{3}$ or $\mathrm{Na}_{2} \mathrm{~S}_{2} \mathrm{O}_{3}$ to improve AgNPs extraction efficiency. The maximum extraction efficiency for AgNPs was measured at $\mathrm{pH} \sim 3.0-3.5$. The technique was first used for the separation of NPs [69]. MSE investigated the extraction of Ag NPs from nine municipal wastewater treatment plants (WWTPs) in Germany. In the absence of Triton X-114 as a surfactant, EDTA was used as a chelating agent. Then dissolve ML in ethanol and be measured by ETAAS. The D.L. registered $0.7 \mathrm{ng} / \mathrm{L}$ [70]. In the other study, Triton-X114 was used to remove AgNPs from real samples into an ML, which was collected after a 10 -minute incubation at $40{ }^{\circ} \mathrm{C}$ and centrifugation. This 
indicates a low D.L. of $2 \mathrm{ng} / \mathrm{L}$ and a preconcentration factor of 242, indicating that AgNPs are not removed when thiocyanate is present [77]. Copper oxide NPs (CuONPs) are separated from water using the MSE technique. $\mathrm{NaCl}(10 \mathrm{mM}-0.2 \mathrm{M})$ and $\mathrm{pH}$ were set to 9.0 using Triton X-114. The separated layer was improved by centrifugation $\left(25^{\circ} \mathrm{C}, 10 \mathrm{~min}, 3000\right.$ rpm) after heating at $45{ }^{\circ} \mathrm{C}$ for 40 minutes. After that, the ML was collected for examination and CuONPs determination. FT-IR, TEM, zeta potential, and an N2Brunauer-Emmett-Teller (BET) surface area sample were used in the investigation. During digestion with both hydrogen peroxide and nitric acid within a microwave device, the $\mathrm{Cu}$ sample was determined by ICP-MS. This research improves the MSE process with a high potential for nanoparticle extraction from waste [71]. The CuO NPs were separated from wastewater samples using a specific MSE process. CuONPs are removed using Triton X-114 (0.3 percent w/v) at $\mathrm{pH}$ $8-10$, with $\mathrm{NaCl}$ as a salt. CuONPs were determined using an ICP-MS detector, and particle sizes were calculated using a TEM. The recovery from wastewater solutions has affected over $88 \%$ of $\mathrm{CuO}$ NPs [72]. A preconcentration and selective MSE process of AuNPs from drinking water and ETAAS determination. The process involved chelating AuNPs with Triton X-114 and $\mathrm{Na}_{2} \mathrm{~S}_{2} \mathrm{O}_{3}$ before transferring them to the ML. The TEM analysis revealed that the extraction method had no impact on the nano composition of AuNPs, implying a cost-effective separation method. Prior to determining this, ETAAS was able to take small sample size measures using a large number of Micelle Mediate Reagents [73]. The second role of NPs is to behave as a layer to protect rare species in the ML. The use of NPs for trace element separation and preconcentration in real samples is well known [74]. Modified or unmodified AgNPs were applied in MSE and had successful results for preconcentration of a tiny concentration of metal ions. Modified AgNPs have the ability to carry metallic ions like $\mathrm{Cu}(\mathrm{II})$ and $\mathrm{Ni}(\mathrm{II})$ ions and separate these ions by using the sodium salt of 2-mercapto ethane sulfonic acid and Triton X-114. This procedure allows us to transfer tiny amounts of metal ions into the ML. The D. L. is 2.4 and $2.1 \mathrm{ng} / \mathrm{L}$ for $\mathrm{Cu}(\mathrm{II})$ and $\mathrm{Ni}(\mathrm{II})$, respectively [75]. On the other hand, for extraction, $\mathrm{Cr}(\mathrm{III})$ and $\mathrm{Cr}(\mathrm{VI})$ used unmodified AgNPs as a support carrier with the present Triton $\mathrm{X}-114$ [76].

Many examples were reported in Table 3. In addition, these NPs help to extract and separate biomolecules and organic compounds. For determination of vitamin B12 in urine and plasma, using Triton-X100 as a surfactant and vitamin B12 complexation by silver nanoparticles and chitosan (AgNPs-CH) coupled with MSE. The presented approach was originally followed by fluorimetric detection [83]. The multi-

Table 3 Overview of nanoparticles used as layers in MSE methods

\begin{tabular}{|c|c|c|c|c|c|c|}
\hline Surfactant & Nanoparticle & Extracted & LOD (ng/L) & Detector & Samples & Ref. \\
\hline \multirow{8}{*}{ Triton-114 } & AgNPs & $\operatorname{Ag}(I)$ & 0.15 & ETAAS & Water & 104 \\
\hline & AgNPs & $\mathrm{Cu}(\mathrm{II}) \mathrm{Ni}(\mathrm{II})$ & 2.42 .1 & ETAAS & Water, wine and beer & 75 \\
\hline & AgNPs & $\mathrm{Cr}(\mathrm{III})+\mathrm{Cr}(\mathrm{VI})$ & 2.0 & ETAAS & Water, wine and beer & 76 \\
\hline & $\mathrm{ZrO}_{2} \mathrm{NPs}$ & $\mathrm{Pb}(\mathrm{II})$ & 2.2 & ETAAS & Water, tea and rice & 86 \\
\hline & $\mathrm{SnO}_{2}$ & $\mathrm{Cu}(\mathrm{II}) \mathrm{Fe}(\mathrm{III})$ & 9070 & FAAS & Tap, well and lake water & 87 \\
\hline & GONPs & $\mathrm{V}$ (total) & 20 & ETAAS & Water, beer and canned drinks & 88 \\
\hline & $\mathrm{Al}_{2} \mathrm{O}_{3} \mathrm{NPs}$ & $\mathrm{Co}(\mathrm{II}) \mathrm{Ni}(\mathrm{II}) \mathrm{Cu}(\mathrm{II})$ & 2.62 .82 .5 & ETAAS & Natural water & 89 \\
\hline & $\mathrm{Fe}_{2} \mathrm{O}_{3} @ \mathrm{C} \mathrm{MNPs}$ & Different organics & Different & LC & River and lake water & 90 \\
\hline \multirow{2}{*}{ Triton X-100 } & AgNPs & Vitamin B12 & 36 & Fluorimeter & Urine and plasma & 83 \\
\hline & TiO2NPs & $\mathrm{Zn}(\mathrm{II})$ & 330 & Colorimeter & Water, milk and tablets $\left(\mathrm{ZnSO}_{4}\right)$ & 91 \\
\hline Triton X-45 & GONPs & $\mathrm{Cr}(\mathrm{III})$ & 5.0 & ETAAS & Potable water and seawater & 92 \\
\hline SDS & NDs & Fluoranthene & 17 & Fluorimeter & River water & 84 \\
\hline SDS/PONPE 7.5 & $\mathrm{Fe}_{3} \mathrm{O}_{4} \mathrm{NPs}$ & Alfuzosin Doxazosin & 160210 & Fluorimeter & Urine, tablets and human plasma & 93 \\
\hline PEG 6000 & RGO/CHNPs & Veltapasvir & 40 & Fluorimeter & Plasma, urine and tablets & 85 \\
\hline
\end{tabular}

Note: ETAAS: Electro thermal atomic absorption spectroscopy; FAAS: Flame atomic absorption spectroscopy; LC: Liquid chromatography; LOD: Limit of detection; $\mathrm{Fe}_{2} \mathrm{O}_{3} @ C$ MNPs: Highly hydrophobic polysiloxane-coated core-shell; $\mathrm{Fe}_{2} \mathrm{O}_{3} @ \mathrm{C}$ : Magnetic nanoparticles; NDs: Nano diamonds;

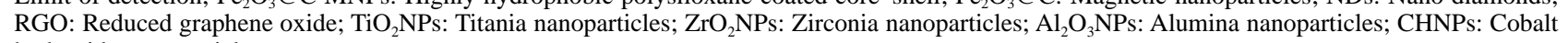
hydroxide nanoparticles. 
walled carbon nanotubes (MWCNTs), nanodiamonds (NDs), and hybrid nanoparticles (NDs-MWCTNTs) were also compared as a catalyst phase in the micellar system of the anionic surfactant SDS. Also, in the end, they reached the conclusion that NDs were ideal for the separation of Fluoranthene and changing the MS procedure [84]. On the other hand, the antihepatitis C medicine Veltapasvir was predicated on using a non-ionic surfactant, polyethylene glycol 6000 (PEG 6000), graphene oxide (RGO), with cobalt hydroxide nanoparticles (CHNPs) as a catalyst layer. The MSE was very good at removing impurities and eliminating interference from co-existing species. The purpose of this study is the determination of the drug in pharmaceutical tablets by fluorimetric detection [85]. Table 3 lists the examples that were chosen. This combination is often seen in the review as a modern nano-extraction technique dubbed 'extracting nanomaterials from the micellar system'.

The chemical characteristics of NPs dictate the third function of employing them. In MSE, they were detecting substances. NPs have also demonstrated significant advantages over innovative analytical approaches, particularly MSE procedures, according to sensing activities. The size, structure, and interparticle length play a role in the high absorption coefficient and color-tunable photocatalytic action. A growing interest in AuNPs-based sensors has resulted [94]. Table 4 summarizes some of the cases. Several AuNPs-based spectrometric sensors were documented for the determination of various analytes. The quantification of $\mathrm{Hg}(\mathrm{II})$ ions has piqued their interest in them [95]. Hg(II) ions can now be separated and quantified by applying a new process. The use of a hyperbranched thermoresponsive polymer for MSE, as well as a spectrometric probe (AuNPs) for detection of $\mathrm{Hg}(\mathrm{II})$ ions. The polymers contain three substances. Hyperbranched poly ethylenimine (HPEI) with isobutyramide (IBAm) end groups (HPEI-IBAm) coated with AuNPs were used to enrich and isolate $\mathrm{Hg}(\mathrm{II})$ using quick precipitation and centrifugation. The work's benefit was that their colorimetric sensor's color shifted from red to fawn. They are also more responsive than the two most commonly used colorimetric sensors (which change color depending on the aggregation of AuNPs) [96]. This simple concept resulted in a more sensitive and selective MSE method [97]. AuNPs are also used as colorimetric probes for AgNPs extraction. Triton X-114 was used for the extraction process, but the colorimetric test consisted of Tween-20 remaining stable AuNPs (Tween-20AuNPs). Following phase separation, the focused AgNPs oxidized into AgI ions in the ML. Then, increase Tween-20 AuNPs aggregation. As a result, extraction efficiency improved [98]. This branch can act as Fig. 4.

\section{Separation bioactive molecules by MSE}

Many researchers have used MSE for the separation of bioactive molecules like amino acids, proteins, vitamins, enzymes, drugs, and pro-vitamins. This part and Table 5 discuss medications and vitamins in particular. Medical determination in the biological matrix is important in a number of biochemical fields, medicine, and pharmacy, including toxicity tests, drug production, and controlling drug concentration [106]. Patients also use more than one medication at a time that can interact with various tests. There are several major differences between humans, and drug levels can vary greatly between individuals [107]. Since the clinical application of a drug is determined by its level in biological fluids, and accurate method of measurement is essential during treatment [109].

Table 4 MSE approaches employing selective nanoparticles as sensing probes

\begin{tabular}{ccccccc}
\hline Surfactant & NPs & Extracted & LOD $(\mathrm{ng} / \mathrm{L})$ & Detector & samples & Ref. \\
\hline HPEI-IBAm & AuNPs & Hg(II) & 0.22 & Colorimeter & Water & 96 \\
& AuNPs & Hg(II) & 2.00 & Colorimeter & Water & 97 \\
\multirow{3}{*}{ Triton X-114 } & AuNPs & AgNPs & 1.00 & Colorimeter & Water & 98 \\
& AgNPs & Sulfadiazine & 2.80 & LSPR & Biological & 99 \\
& AgNPs & Cu(II) & 0.10 & SPR & Food & 100 \\
Triton X-100 & CuRPNs & Citrate & 1.70 & Colorimeter & Food + drug & 101 \\
& CuRPNs & Sulfide & 0.40 & Colorimeter & Water & 102 \\
SDS & AuNPs & Mg(II) & 0.10 & SERS & Water & 103 \\
\hline
\end{tabular}

Note: SERS, Surface-enhanced Raman scattering, SPR, Surface Plasmon resonance, LSPR, Localized surface Plasmon resonance; MG, Malachite Green, CURNPs, Curcumin nanoparticles 


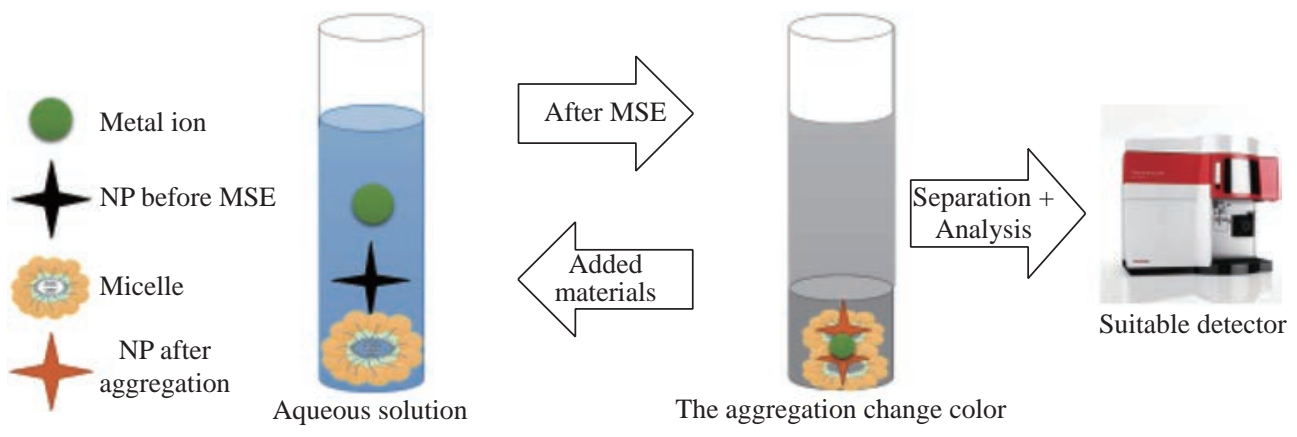

Fig. 4 NPs as optical sensing in a micellar system.

Table 5 Application of bioactive molecules in the MSE method

\begin{tabular}{|c|c|c|c|c|c|}
\hline Surfactant & Analytes & Temperature $\left({ }^{\circ} \mathrm{C}\right)$ & Recovery (\%) & Detector & Ref. \\
\hline \multirow{14}{*}{ Triton-114 } & Triptonide & 55 & 96 & UV spectrophotometry & 108 \\
\hline & Bisoprolol & 55 & 61 & LC/MS & 116 \\
\hline & Antazoline & 40 & -- & LC/MS & 117 \\
\hline & Paracetamol & 25 & -- & FL & 118 \\
\hline & Meloxicam & 35 & 92 & HPLC/ UV & 119 \\
\hline & Venlafaxine & 40 & 89 & HPLC/ FL & 120 \\
\hline & Arbidol & 45 & 90 & HPLC/ UV & 121 \\
\hline & Larotaxel & 45 & 93 & HPLC/ UV & 124 \\
\hline & Vitamin $\mathrm{K}_{3}$ and 1,4-naphthoquinone & 25 & -- & UV spectrophotometry & 125 \\
\hline & Vitamin $\mathrm{B}_{1}$ & 40 & $93-107$ & Spectrofluorometric & 126 \\
\hline & Cefixime & 25 & $95-131$ & UV & 140 \\
\hline & 21 Antidepressants & $15-23$ & $94-111$ & LC-MS & 130 \\
\hline & Phenylalanine & 40 & $94.1-107.7$ & Scanometry & 134 \\
\hline & Sulphadimidine sodium & 50 & $94.5-101.3$ & UV & 143 \\
\hline \multirow{5}{*}{ Triton-100 } & Isoniazid & 70 & 83 & HPLC/ UV & 122 \\
\hline & Beta-carotene & 67 & 99 & UV-Vis & 141 \\
\hline & Seven sulphonamides & -- & $67.0-105.7$ & HPLC/ UV & 123 \\
\hline & Vitamins $A$ and $E$ & 70 & $90.2-99.2$ & MLC & 142 \\
\hline & Vitamins $\mathrm{B}_{1}, \mathrm{~B}_{2}, \mathrm{~B}_{3}$ and $\mathrm{B}_{4}$ & 50 & $78-88$ & HPLC & 137 \\
\hline \multirow{2}{*}{ Genapol X-080 } & Vitamins $\mathrm{A}$ and $\mathrm{E}$ & 50 & 85.582 .6 & HPLC/ UV & 127 \\
\hline & Flurbiprofen & 50 & - & HPLC/ UV & 128 \\
\hline PONPE 7.5 & Terazosin hydrochloride & -10 & $90-112$ & Spectrofluorometric & 129 \\
\hline \multirow{2}{*}{ SDSA } & Vitamin E & 10 & $80-85$ & HPLC-UV-FI & 131 \\
\hline & Vitamin $B_{6}$ & 40 & 88-104 & UV-Vis & 132 \\
\hline PEG-6000 & Vitamin $\mathrm{B}_{9}$ & 40 & $95.6-104.2$ & HPLC & 138 \\
\hline
\end{tabular}

Note: PEG-6000: Polyethylene glycol 6000; MLC: Micellar liquid chromatography; Vitamin $\mathrm{B}_{1}$ : Thiamine; Vitamin $\mathrm{B}_{3}$ : Niacinamide; Vitamin $\mathrm{B}_{6}$ : Pyridoxine; Vitamin $\mathrm{B}_{2}$ : Riboflavin.

Another issue is that medication levels in human fluids and tissue are significantly lower, necessitating preconcentration prior to determination. Sample solution analysis can interfere with chemicals from biological tests such as organic matter, macromolecules, and salts [110-113]. 
Isolating proteins with organic solvents or adjusting the $\mathrm{pH}$ of the test is one of the most successful sample preparation techniques. However, in other circumstances, a specific method of preparation is insufficient for a complete study. As a result, numerous extraction procedures apply during sample preparation [114, 115]. Table 5 shows many bioactive substances used in MSE with different parameters. Also, on the other hand, bioactive molecules are used as selective ligands to reduce pollution from organic reagents. Aspirin [7], cysteine [133], and 4-(2-chloroacetamido)salicylic acid [135] use to determine tiny amounts of copper in different testes by Triton X-100, SDS, and Triton X-114, respectively. The findings have shown the efficacy of MSE in the preconcentration and quantitative extraction of copper. The methods were utilized successfully to detect $\mathrm{Cu}$ (II) in food and drug samples with high recovery, without cumbersome preseparation methods, and costly equipment.

Vitamins play a specific role in the energy synthesis and the health of organs such as the skin, muscles, eyes, and livers. In various metabolic reactions, such as carbohydrates, lipids, and protein metabolism, they serve as a primer for coenzymes and enzyme cofactors [139]. Vitamin analysis in samples (food, urine, and blood) complicate by many factors, including low and variable concentrations, interference effects, the existence of multiple bioavailable forms (vitamers), reactive structure, and molecular heterogeneity [136].

As a result, researchers face the challenge of developing and validating quick, cost-effective, and reliable methodological approaches for multivitamin detection. However, due to the restricted transfer of vitamin molecules to the surfactant by modern MSE, obtaining an acceptable preconcentration parameter is challenging. To resolve the issue, vitamins $B_{1}$ and $\mathrm{B}_{2}$ were successfully extracted from a complex food sample using a modified MSE approach involved in the complex silver ion formation with vitamins. This research focuses on the ability of vitamin molecules to form complexes with silver ions in exchange for improved extraction efficiency [136].

Another study used Triton X-100 and sodium salt of 1-Heptanesulfonic acid as an ion pair agent to extract vitamins from biosamples using the MSE method. Some vitamins have extracted using ion-pair micellar system extraction (IP-MSE), which is based on the creation of ion pairs (IP) between analytes and an IP reagent. Since analytes ionize in an acidic medium and form positively charged ions, no analytes were extracted into the ML without the use of an IP reagent [137]. More information are reported in Table 5. The methods used for the extraction of vitamins rely on acid hydrolysis or enzyme therapy, so that all bonded vitamins come off the matrix, or all potential vitamins reduce into fewer forms, such as mono or di glutamate from polyglutamate folates. Precipitation of proteins is also a way of removing linkages between peptides and vitamins. Vitamins use in some papers as chelating reagents. Vitamin C is used to separate silver ions from biological samples in the presence of Triton X-100 as a surfactant. This procedure obtained a low detection limit and a high preconcentration factor [39].

\section{Conclusions}

Analytes are critical parameters in any separation process. Moreover, the form of surfactant used and its amount, $\mathrm{pH}$, temperature, heating time, and the additional salts, influence factors on the MSE results. The type of used surfactant is the determination by the analytes. In the field of micellar system extraction, many recent and exciting advancements made in the last decade. In the literature, for the application of NPs in MSE can be found three procedures:

1. NPs are directly preconcentrated.

2. MSE is used to absorb inorganic or organic materials, such as nano-sized sorbents such as $\mathrm{ZrO}_{2}$, $\mathrm{TiO}_{2}, \mathrm{Al}_{2} \mathrm{O}_{3}$, and others.

3. Optical sensing, for example, the use of AuNPs as colorimetric nano-probes.

Vitamins and medications are extracted in two ways: directly extraction and acting as a cheating reagent.

Innovative MSE methods in the ultra-trace analysis of different species have a lot of promise in all ways. In general, at around $15-20{ }^{\circ} \mathrm{C}$, the extraction temperature was above the CT of the surfactant. When extracting bioactive molecules, the most commonly used temperature is less than $70{ }^{\circ} \mathrm{C}$. The addition of salting-out at a specific level affects the CMC of the surfactant, assisting the extraction method. MSE is also less hazardous than other forms of extraction methods. As a result of its simplicity, speed, low environmental impact, accuracy, and high optimization capabilities, researchers believe that MSE widely uses in nano and bio applications. Researchers are also increasingly interested in developing new separation techniques. An increasing interest in "green chemistry" is the main 
reason for research on the subject. Recent articles on MSE improvement, such as RMSE and Dual-CPE, demonstrate that the proposed method is gaining popularity and is becoming an effective separation technique in chemical analysis.

\section{Acknowledgments}

The writers acknowledge financial assistance from the Gifted Students' School in Al-Najaf and Al-Qasim Green University.

\section{Conflict of Interests}

The authors declare that they have no conflicts of interest.

\section{References}

[1] R. Sankaran, J.H. Bong, Y.H. Chow, et al., Reverse Micellar System in Protein Recovery - A Review of the Latest Developments, Current Protein and Peptide Sciece, 2019, 20: 1012-1026.

[2] S. Raja, V.R. Murty, V. Thivaharan, Aqueous two phase systems for the recovery of biomolecules - A review, Sci. Tchnol., 2012, 1(1): 7-16.

[3] P. Samaddar, K. Sen, Cloud point extraction: a sustainable method of elemental preconcentration and speciation, $J$. Ind. Eng. Che., 2014, 20 (4): 1209-1219.

[4] K. Pytlakowska, V. Kozik, M. Dabioch, Complex-forming organic ligands in cloud point extraction of metal ions: a review, Talanta, 2013, 110: 202-228.

[5] E.A. Azooz, F.A. Wannas, S.K. Jawad, Developed Cloud Point Extraction Coupled with Onium System for Separation and Determination Cobalt in Biological Samples, Research Journal of Pharmacy and Technology, 2021, 14(2): 594-598.

[6] W.I. Mortada, M.M. Hassanien, A.A. El-Asmy, Cloud point extraction of some precious metals using Triton $\mathrm{X}-114$ and a thio amide derivative with a salting-out effect, Egypt. J. Basic App. Sci. 2014, 1(3-4): 184-191.

[7] E.A. Azooz, J.R. Moslim, S.M. Hameed, et al., Aspirin in Food Samples for Separation and Micro Determination of Copper (II) using Cloud Point Extraction/Solvation Method, Nano Biomed. Eng., 2021, 13(1): 62-71.

[8] S.K. Jawad, M.U. Kadhium, A.S. Alwan, Incorporation Solvation with Cloud Point Extraction Method for Separation and Spectrophotometric Determination of Cerium (III), Oriental Journal of Chemistry, 2017, 33(4): 1985-1993.

[9] S.K. Jawad, M.U. Kadhium, E.A. Azooz, Application Cloud Point Extraction Method Joined with Liquid Ion Exchange for Selective Determination of $\mathrm{Fe}^{3+}$ and $\mathrm{Hg}^{2+}$ In Real Samples, Journal of Engineering and Applied Silences, 2019, 14(11): 3514-3521.

[10] S.K. Jawad, E.A. Azooz, a new Approach for Separation, Extraction and Determination of Zinc in Different Samples using Cloud-Point Extraction Coupled with spectrophotometry, FIRE Journal of Science and Technology, 2015, 3: 261-273.

[11] S.K. Jawad, M.O. Kadhium, E.A. Azooz, Incorporation of onium system with cloud point extraction and determination of iron (III) and mercury (II) in different samples. Oriental Journal of Chemistry, 2017, 33(4): 1879-1889.

[12] S.K. Jawad, A.S. Abed, Sensitive Cloud Point Extraction Methodology for Separation Preconcentration of Co(II) Followed by Spectrophotometric Determination in Different Samples, Chemical and Process Engineering Research, 2015, 33: 22-31.

[13] E.A. Azooz, J.R. Moslim, S.K. Jawad, Cloud Point Extraction Methodology for Separation, Extraction and Preconcentration of Mn(VII) Coupled with Spectroscopy for Determination in Different Samples, Biochem Cell. Arch. 2020, 20(1): 2641-2648.

[14] N. Dalali, N. Javadi, Y.K. Agrawal, On-line incorporation of cloud point extraction in flame atomic absorption spectrometric determination of silver, Turk J Chem, 2008, 32: $561-570$

[15] J.L. Manzoori, H. Abdolmohammad-Zadeh, M. Amjadi, Ultra trace determination of silver in water samples by electrothermal atomic absorption spectrometry after preconcentration with a ligand-less cloud point extraction methodology, J Hazard Mater, 2007, 144: 458-463.

[16] J. Miura, H. Ishii, H. Watanabe, Extraction and separation of nickel chelate of 1-(2-thiazolylazo)-2-naphthol in nonionic surfactant solution. vol 25. Japan soc analytical chem 26-2 nishigotand 1 chome shinagawa-ku, Tokyo, 1976: 141.

[17] R.I. Sulaiman, S.R. Adeyemi, S.W. Abraham, I.M.A. Hasan, Liquid-liquid extraction of chlorophenols from wastewater using hydrophobic ionic liquids, J. Mol. Liq., 2019, 294: 111680.

[18] F.A. Wannas, E.A. Azooz, S.K. Jawad, Liquid Ion Exchange with Spectrophotometric Method for Separation and Determination W(VI), Journal of Adv. Research in Dynamical \& Control Systems, 2019, 11(7): 260-269.

[19] S.K. Jawad, S.M. Hameed, S.A. Hussain, Liquid Ion Exchange Application for Micro Amount Separation and Determination of $\mathrm{Ca}(\mathrm{II})$ and $\mathrm{Mg}(\mathrm{II})$ as Anions Species with EDTA, Oriental J. of Chemistry, 2017, 33(5): 24212429.

[20] X. Yang, Z. Jia, X. Yang, Cloud point extraction flame atomic absorption spectrometry for pre-concentration and determination of trace amounts of silver ions in water samples, Saudi Journal of Biological Sciences, 2017, 24: 589-594.

[21] M.A. Bezerra, M.A.Z. Arruda, S.L.C. Ferreira, Cloud point extraction as a procedure of separation and preconcentration for metal determination using spectraanalytical techniques: a review, ppl. Spectrosc. Rev., 2005, 40(4): 269-299.

[22] K.J. Shawket, K.R. Rana, Cloud Point Extraction Coupled with Liquid Ion Exchange for Separation and Determination Mn(VII) in real samples, Research $J$. Pharm. and Tech., 2019, 12(10): 4861-4866.

[23] S.A. Hussain, S.M. Hameed, Solvation Methodology for Separation and Micro Determination of Lead (II) In Different Sample, ARPN Journal of Engineering and Applied Sciences, 2019, 14(5): 1005-1011.

[24] K.J. Shawket, K.R. Rana, Incorporation Cloud Point Extraction with Liquid Ion Exchange for Separation and Determination of Iron (III), ARPN Journal of Engineering and Applied Sciences. 2019, 14(10): 1963-1942.

[25] S.K. Jawad, F.H. Hayder, Determination and Extraction of Zinc (II) Via Cloud Point Methodology, International Journal of Applied Chemical Sciences Research, 2015, 3(1): 1-12.

[26] C.B. Ojeda, F.S. Rojas, J.M.C. Pavón, Preconcentration of cadmium in environ-mental samples by cloud point extraction and determination by FAAS, Am. J. Anal. Chem. 2010, 1: 127-134. 
[27] H.C. Rezend, C.C. Nascentes, N.M.M. Coe-lho, Cloud point extraction for determination of cadmium in soft drinks by thermospray flame furnace atomic absorption spectrometry, Microchem. J., 2011, 97: 118-121.

[28] N.I. Mohd, N.N.M. Zain, M. Raoov, S. Mohamad, Determination of carcinogenic herbicides in milk samples using green non-ionic silicone surfactant of cloud point extraction and spectrophotometry, Royal Society Open Science, 2018, 5(4): 171500.

[29] W. Liu, M. Xie, X. Hao, Rapid synergistic cloud point extraction for simultaneous determination of five polar phenols in environmental water samples via high performance liquid chromatography with fluorescence detection, Microchemical Journal, 2021, 164: 105963.

[30] M.S. Noorashikin, A.B. Nur Nadiah, I. Nurain, et al, Determination of phenol in water samples using cloud point extraction and UV spectrophotometry, Desaliation and Water Treatment, 2016, 57(33): 15486-15494.

[31] M.E. Khalifa, I.M. Kenawy, M.M. Hassanien, M.M. Elnagar, Mixed micelle-mediated extraction and separation of scandium from yttrium and some lanthanide ions, Anal. Sci., 2016, 32(4): 395-400.

[32] S.K. Jawad, M.U. Kadhium, E.A. Azooz, Separation and Spectrophotometric Determination of Iron (III) and Mercury (II) via Cloud Point Extraction with New AzoDerivative. Eurasian Journal of Analytical Chemistry, 2018, 13(5): 1-11.

[33] W.I. Mortada, M.M. Hassanien, A.A. El-Asmy, Speciation of platinum in blood plasma and urine by micelle-mediated extraction and graphite furnace atomic absorption spectrometry, J. Trace Elem. Med Biol. 2013, 27(4): 267-272.

[34] X.B. Yin, J.M. Guo, W. Wei, Dual-cloud Point Extraction and Tertiary Amine Labeling for Selective and Sensitive Capillary Electrophoresis-electrochemiluminescent Detection of Auxins. Journal of Chromatography A, 2010, 1217(8): 1399-1406.

[35] S. Khan, T.G. Kazi, J.A. Baig, et al, Cloud Point Extraction of Vanadium in Pharmaceutical Formulations, Dialysate and Parenteral Solutions Using 8-hydroxyquinoline and Nonionic Surfactant. J. Hazard. Mater., 2010, 182(1-3): 371-376.

[36] L.L. Wang, J.Q. Wang, Z.X. Zheng, P. Xiao, Cloud Point Extraction Combined with High-performance Liquid Chromatography for Speciation of Chromium (III) and Chromium (VI) in Environmental ediment Samples. Journal of Hazardous Materials, 2010, 177.

[37] D.G. Santarossa, M.C. Talio, L.P. Fernández, Aluminum Traces Determination in Biological and Water Samples Using a Novel Extraction Scheme Combined with Molecular Fluorescence. Microchemical Journal, 2016, 129: 274-280.

[38] M.S. Noorashikin, M. Raoov, S. Mohamad, M.R. Abas, Cloud Point Extraction of Parabens Using Non-ionic Surfactant with Cyclodextrin Functionalized Ionic Liquid as a Modifier. International Journal of Molecular Sciences, 2013, 14(12): 24531-24548.

[39] E.A. Azooz, F.A. Wannas, R.K. Ridha, et al., A Green Approach for Micro Determination of Silver (I) in Water and Soil Samples Using Vitamin C, Analytical and Bioanalytical -Chemistry Research, 2022, 9(1): 90-97.

[40] T. Shafiq, M. Uzair, M.J. Iqbal, et al., Green Synthesis of Metallic Nanoparticles and Their Potential in Bio-Medical Applications. Nano Biomed. Eng., 2021, 13(2): 191-206.

[41] M. Hosseini, A. Naderi, A. Rezaei, et al., Application of an In-situ Solvent Formation Microextraction Technique Using the Functionalized Ionic Liquids (FILs) as a Green Extractant for Cadmium Determination at Trace Levels in Real and Saline Samples, Analytical and Bioanalytical Chemistry Research, 2022, 9(1): 33-44.
[42] J.F. Liu, R. Liu, Y.G. Yin, G.B. Jiang, Triton X-114 based cloud point extraction: a thermo reversible approach for separation/concentration and dispersion of nanomaterials in the aqueous phase, Chem. Commun. 2009, 12: 15141516.

[43] W. Mortada, I. Kenawy, G. El-Gamal, S. Moalla, a micro mixed micelle-mediated preconcentration procedure for spectrophotometric determination of uranium in real and synthetic samples, J. Radioanal. Nucl. Chem. 2017, 313(1): 69-77.

[44] E.K. Paleologos, D.L. Giokas, M.I. Karayannis, Micellemediated separation and clod-point extraction, TrAC, Trends Anal. Chem. 2005, 24(5): 426-436.

[45] F. Ahmadi, A.K. Mohammadi, K. Niknam, MicelleMediated Extraction for Preconcentration and Determination of Copper and Zinc in Real Samples, Eurasian Journal of Analytical Chemistry, 2007, 2(3): 118-133.

[46] K.J. Shawket, A.A. Ebaa, cloud point extraction method for separation and pre concentration of $\mathrm{Mg}(\mathrm{II})$ as anion coupled with spectrophotometric applications, Journal of Research in Applied, 2015, 1(2): 119-134.

[47] G. Blanchet-Chouinard, D. Larivière, Determination of $\mathrm{Pb}$ in environmental samples after cloud point extraction using crown ether, Talanta, 2018, 179: 300-306.

[48] Z.A. Hammood, I.R. Ali. N.H. Ali, et al., Liquid ion exchange methodology for extraction $\mathrm{Cr}(\mathrm{VI})$ using azo derivative compound, Materials Today, 2021, 43(2): 2156-2161.

[49] C. Labrecque, S. Potvin, L. W. veille', et al, Cloud point extraction of uranium using H2DEH[MDP] in acidic conditions, Talanta, 2013, 107: 284-291.

[50] A.M. Hyde, S.L. Zultanski, J.H. Waldman, et al., General principles and strategies for salting-out in formed by the Hofmeister series, Org. Process Res. Dev. 2017, 21(9): 1355-1370.

[51] M. Noorashikin, S. Mohamad, M. Abas, Extraction and Determination of Parabens in Water Samples Using an Aqueous Two-phase System of Ionic Liquid and Salts with beta-cyclodextrin as the Modifier Coupled with High performance Liquid Chromatography. Analytical Methods, 2014, 6(2): 419-425.

[52] J. Dong, K.B. Sharpless, L. Kwisnek, et al, SuFEx-ased Synthesis of Polysulfates. Angew. Chem. Int. Ed., 2014, 53: 9466-9470.

[53] X. Peng, H. Xu, X. Yuan, et al., Mixed reverse micellar extraction and effect of surfactant chain length on extraction efficiency. Sep. Purif. Technol., 2016, 160: 117122.

[54] J. Michizoe, H. Ichinose, N. Kamiya, et al., Biodegradation of phenolic environmental pollutants by a surfactant-laccase complex in organic media. J. Biosci. Bioeng., 2005, 99(6): 642-647.

[55] N. Sato, M. Mori, H. Itabashi, Cloud point extraction of $\mathrm{Cu}(\mathrm{II})$ using a mixture of triton $\mathrm{X}-100$ and dithizone with a salting-out effect and its application to visual determination, Talanta, 2013, 117: 376-381.

[56] A.Q. Shah, T.G. Kazi, J.A. Baig, et al., Total Mercury Determination in Different Tissues of Broiler Chicken by Using Cloud Point Extraction and Cold Vapor Atomic Absorption Spectrometry. Food and Chemical toxicology, 2010, 48(1): 65-69.

[57] M. Ezoddin, F. Shemirani, R. Khani, Application of Mixed-micelle Cloud Point Extraction for Speciation Analysis of Chromium in Water Samples by Elecrothermal Atomic Absorption Spectrometry. Desalination, 2010, 262(1-3): 183-187.

[58] N.R. Bader, K. Edbey, U. Telgheder, Cloud Point Extraction as a Sample Preparation Technique for Trace Element Analysis: n Overview. Journal of Chemical and 
Pharmaceutical Research, 2014, 6(2): 496-501.

[59] S. Nobuko, M. Masanobu, I. Hideyuki, Cloud Point Extraction of Cu(II) Using a Mixture of Triton X-100 and Dithizone with a Salting-out Effect and Its Application to Visual Determination. Talanta, 2013, 17: 376-381.

[60] T. Tanaka, P. Decuzzi, M. Cristofanilli, et al. Nanotechnology for breast cancer therapy, Biomed Microdevices, 2009, 11(1): 49-63.

[61] P.F. Zhang, G. Liu, X.Y. Chen, Nano biotechnology: cell membrane-based delivery systems, Nano Today, 2017, 13: 7-9.

[62] N. Sozer, J.L. Kokini, Nanotechnology and its applications in the food sector, Trends Biotechnol. 2009, 27: 82-89.

[63] A. Jain, S. Ranjan, N. Dasgupta, Nanomaterials in food and agriculture: an overview on their sfety concerns and regulatory issues, Crit. Rev. Food Sci. Nutr. 2018, 58(2): 297-317.

[64] P.C. Ray, H. Yu, P.P. Fu, Toxicity and environmental risks of nanomaterials: challenges and future needs, J. Environ. Sci. Health Part C, 2009, 27(1): 1-35.

[65] D. Zirkler, F. Lang, M. Kaupenjohann, “Lost in filtration"-The separation of soil colloids from larger particles, Colloids Surf., A, 2012, 399: 35-40.

[66] M. Roca, N.H. Pandya, S. Nath, Linear assembly of gold nanoparticle clusters via centrifugation, Langmuir, 2009, 26(3): 2035-2041.

[67] K.L. Chen, M. Elimelech, Interaction of fullerene (C60) nanoparticles with hemic acid and alginate coated silica surfaces: measurements, mechanisms, and environmental implications, Environ. Sci. Technol. 2008, 42(20): 76077614.

[68] J.B. Chao, J.F. Liu, S.J. Yu, et al, Speciation analysis of silver nanoparticles and silver ions in antibacterial products and environmental waters via cloud point extraction-based separation, Anal. Chem. 2011, 83(17): 6875-6882.

[69] J.F. Liu, J.B. Chao, R. Liu, et al, Cloud point extraction as an advantageous preconcentration approach for analysis of trace silver nanoparticles in environmental waters, Anal. Chem. 2009, 81(15): 6496-6502.

[70] L. Li, G. Hartmann, M. Döblinger, et al, Quantification of nanoscale silver particles removal and release from muniipal wastewater treatment plants in Germany, Environ. Sci. Technol. 2013, 47(13): 7317-7323.

[71] S.M. Majedi, B.C. Kelly, H.K. Lee, Evaluation of a cloud point extraction approach for the preconcentration and quantification of trace $\mathrm{CuO}$ nanoparticles in environmental waters, Anal. Chim. Acta, 2014, 814: 3948.

[72] J. Liu, J. Sun, G. Jiang, Use of cloud point extraction for removal of Nano sized copper oxide from wastewater, Chin. Sci. Bull. 2010, 55(4-5): 346-349.

[73] G. Hartmann, M. Schuster, Species selective preconcentration and quantification of gold nanoparticles using cloud point extraction and electro thermal atomic absorption spectrometry, Anal. Chim. Acta 2013, 761: 2733.

[74] B. Hu, M. He, B. Chen, Nanometer-sized materials for solid-phase extraction of trace elements, Anal. Bioanal. Chem. 2015, 407: 2685-2710.

[75] I. López-García, Y. Vicente-Martínez, M. HernándezCórdoba, Determination of very low amounts of free copper and nickel ions in beverages and water sample using cloud point extraction assisted by silver nanoparticles, Anal. Methods, 2015, 7: 3786-3792.

[76] I. López-García, Y. Vicente-Martínez, M. HernándezCórdoba, Non-chromatographic speciation of chromium at sub-ppb levels using could point extraction in the presence of unmodified silver nanoparticles, Talanta,
2015, 132: 23-28.

[77] I. López-García, Y. Vicente-Martínez, M. HernándezCórdoba, Speciation of silver nanoparticles and Ag(I) species using cloud point extraction followed by electro thermal atomic absorption spectrometry, Spectrochim. Acta B. 2014, 101: 93-97.

[78] S. Murugadoss, D. Lison, L. Gdderis, Toxicology of silica nanoparticles: an update, Arch. Toxicol. 2017, 91(9): 2967-3010.

[79] S.N.A. Shah, Z. Shah, M. Hussain, Hazardous effects of titanium dioxide nanoparticles in ecosystem, Bioinorg. Chem. Appl. 2017, 2017: 1-12.

[80] G.S. Simate, S.E. Iyuke, S. Ndlovu, Human health effects of residual carbon nanotubes and traditional water treatment chemicals in drinking water, Environ. Int. 2012, 39(1): 38-49.

[81] M.C. Stensberg, Q. Wei, E.S. McLamore, Toxicological studies on silver nanoparticles challenges and opportunities in assessment, monitoring and imaging, Nanomedicine, 2011, 6(5): 879-898.

[82] X.D. Zhang, H.Y. Wu, D. Wu, Toxicology effects of gold nanoparticles in vivo by different administration routes, Int. J. Nanomed. 2010, 5: 771.

[83] N. Pourreza, R. Mirzajani, J. Burromandpiroze, Fluorescence detection of vitamin B12 in human plasma and urine samples using silver nanoparticles embedded in chitosan in micellar media, Anal. Methods, 2017, 9: 40524059.

[84] E. Caballero-Díaz, B.M. Simonet, M. Valcárcel, Nano diamonds assisted-clod point extraction for the determination of fluoranthene in river water, Anal. Methods, 2013, 5: 3864-3871.

[85] M.M. El-Wekil, H.R.H. Ali, A.A. Marzouk, R. Ali, enhanced dispersive solid phase extraction assisted by cloud point strategy prior to fluorimetric determination of ant hepatitis $\mathrm{C}$ drug Veltapasvir in pharmaceutical tablets and body fluids, RSC Adv. 2018, 8: 13292-13300.

[86] F. Shakerian, S. Dadfarnia, A.M. Haji Shabani, Preconcentration and determination of lead (II) by microextraction based on suspended cation covered zirconia nanoparticles in a surfactant media, Microchim. Acta, 2013, 180: 1225-1232.

[87] S. Nekouei, F. Nekouei, H.İ. Ulusoy, et al, Simultaneous application of cloud point and solid-phase extraction for determination of $\mathrm{F}(\mathrm{III})$ and $\mathrm{Cu}(\mathrm{II})$ ions by using $\mathrm{SnO}_{2}$ Nano powder in micellar medium, Desalin. Water Treat. 2016, 57: 12653-12662

[88] I. López-García, J.J. Marín-Hernández, M. HernándezCórdoba, Graphite furnace atomic absorption spectrometric determination of vanadium after cloud point extraction in the presence of graphene oxide, Spectrochim. Acta B at. Spectrosc. 2018, 143: 42-47.

[89] S. Dadfarnia, F. Shakerian, A.M.H. Shabani, Suspended nanoparticles in surfactant media as a microextraction technique for simultaneous separation and preconcentration of cobalt, nickel and copper ions for electro thermal atomic absorption spectrometry determination, Talanta, 2013, 106: 150-154.

[90] D.L. Giokas, Q. Zhu, Q. Pan, et al, Cloud point-dispersive $\mu$-solid phase extraction of hydrophobic organic ompounds onto highly hydrophobic core-shell Fe2O3@ C magnetic nanoparticles, J. Chromatogr. A., 2012, 1251: 33-39.

[91] N. Pourreza, T. Naghdi, Combined cloud point-solid phase extraction by dispersion of $\mathrm{TiO}_{2}$ nanoparticles in micellar media followed by semi-micro volume UV-vis spectrophotometric detection of zinc, Talanta, 2014, 128: 164-169,

[92] I. López-García, M.J. Muñoz-Sandoval, M. HernándezCórdoba, Cloud point microextraction involving graphene 
oxide for the speciation of very low amounts of chromium in waters, Talanta, 2017, 172: 8-14

[93] N. Gao, H. Wu, Y. Chang, et al., Mixed micelle cloud point magnetic dispersive $\mu$-solid phase extraction of doxazosin and Alfuzosin, Spectrochim. Acta A., 2015, 134: $10-16$

[94] K. Sah, S.S. Agasti, C. Kim, et al., Gold nanoparticles in chemical and biological sensing, Chem. Rev. 2012, 112: 2739-2779.

[95] Y. Ding, S. Wang, J. Li, L. Chen, Nanomaterial-based optical sensors for mercury ions, TrAC Trends Anal. Chem. 2016, 82: 175-190.

[96] Y. Liu, L. Xu, J. Liu, X. Liu, Simultaneous enrichment, separation and detection of mercury (II) ions using cloud point extraction and colorimetric sensor based on thermoresponsive hyper branched polymer-gold nanocomposite, Anal. Methods, 2015, 7: 10151-10161

[97] Z.Q. Tan, J.F. Liu, R. Liu, et al, Visual and colorimetric detection of $\mathrm{Hg}^{2+}$ by cloud point extraction with functionalized gold nanoparticles as a probe, Chem. Commun. 2009: 7030-7032,

[98] Z.H. Wu, W.L. Tseng, Combined cloud point extraction and Tween 20-stabilized gold nanoparticles for colorimetric assay of silver nanoparticles in environmental water, Anal. Methods 2011, 3: 2915-2920.

[99] E. Kazemi, S. Dadfarnia, A.M. Haji Shabani, et al., Indirect spectrophotometric determination of sulfadiazine based on localized surface plasm on resonance peak of silver nanoparticles after cloud point extraction, Spectrochim. Acta A Mol. Biomol. Spectrosc. 2017, 187: 30-35.

[100] N. Pourreza, H. Golmohammadi, Colorimetric sensing of copper base on its suppressive effect on cloud point extraction of label free silver nanoparticles, Anal. Methods, 2014, 6: 2150-2156.

[101] N. Pourreza, H. Sharifi, H. Golmohammadi, Curcumin nanoparticle combined with cloud point extraction for citrate determination in food and drug samples, Microchem. J., 2016, 129: 213-218.

[102] N. Pourreza, H. Golmohammadi, Green colorimetric recognition of trace sulfide ions in water samples using curcumin nanoparticle in micelle mediated system, Talanta, 2014, 119: 181-186.

[103] Y. Jin, P. Ma, F. Liang, et al., Determination of malachite green in environmental water using cloud point extraction coupled with surface-enhanced Raman scattering, Anal. Methods, 2013, 5: 5609-5614.

[104] A. Wimmer, A. Urstoeger, T. Hinke, et al., separating dissolved silver from Nano particulate silver is the key: Improved cloud-point-extraction hyphenated to single particle ICPMS for comprehensive analysis of silverbased nanoparticles in real environmental samples down to single-digit nm particle sizes, Analytica Chimica Acta, 2021, 1150: 238198.

[105] L. Torrent, F. Laborda, E. Marguí, et al., Combination of cloud point extraction with single particle inductively coupled plasma mass spectrometry to characterize silver nanoparticles in soil leachates. Anal Bioanal Chem, 2019, 411: 5317-5329.

[106] I. Pacheco-Fernández, R. González-Martín, F.A. Silva, et al., Insights into coacervative and dispersive liquid-phase microextraction strategies with hydrophilic media - A review, Analytica Chimica Acta, 2021, 1143: 225-249.

[107] G. Kojro, P. Wroczyn' ski, Clou Point Extraction in the Determination of Drugs in Biological Matrices, Journal of Chromatographic Science, 2020, 58(2): 151-162.

[108] Y.W. Wu, Y.Y. Jiang, T.X. Xio, Determination of Triptonide by cloud point extraction combined with MEKC, J. of Separation Science, 2008, 31(5): 865-871.

[109] M.D. Rukhadze, S.K. Tsagareli, N.S. Sidamonidze, et al.,
Cloud-point extraction for the determination of the free fraction of antiepileptic drugs in blood plasma and saliva, Analytical Biochemistry, 2000, 287(2): 279-283.

[110] K.J. Shawket, A.A. Ebaa, Cloud point extraction for separation, preconcentration and extraction of Nickel (II) as chloro anion by use crown ether DB18C6 coupled with spectrophotometric determination, International Journal for Sciences and Technology, 2014, 9(1): 17-23.

[111] F.K. Ahmed, K.H. Moayed, F.A. Hasan, et al., A Simple Pre-Concentration Method for the Determination of Nickel (II) in Urine samples Using UV-Vis Spectrophotometry and Flame Atomic Absorption Spectrometry Techniques, Indones. J. Chem., 2019, 19(3): 638-649.

[112] A.F. Khudhair, S.I. Saeed, Quantitative Analysis of Bismuth (II) Ion by Coupling Turbidy Method with Cloud Point Extraction Mode, International Journal of Science and Research, 2016, 5(4): 218-222.

[113] W. Maret, The metals in the biological periodic system of the elements: concepts and conjectures, Int. J. Mol. Sci. 2016, 17(1): 66-73.

[114] N.D. Jaffer, Clod-point technique for extraction and spectral estimation of zinc (II) in different samples, Biochem. Cell. Arch., 2019, 19(2): 4683-4690.

[115] E.A.J. Al-Mulla, K.W.S. A-Janabi, Extraction of cobalt (II) from aqueous solution by $\mathrm{N}, \mathrm{N}$-carbonyl di-fatty amides. Chinese Chemical Letters, 2011, 22(4): 469-472.

[116] J. Giebułtowicz, G. Kojro, K. Bu's-Kwa'snik, Cloudpoint extraction is compatible with liquid chromatography coupled to elctrospray ionization mass spectrometry for the determination of bisoprolol in human plasma, Journal of Chromatography A, 2015, 1423: 39-46.

[117] J. Giebułtowicz, G. Kojro, R. Piotrowski, et al., Cloudpoint extraction is compatible with liquid chromatography coupled to electrospray ionization mass spectrometry for the determination of antazoline in human plasma; Journal of Pharmaceutical and Biomedical Analysis, 2016, 128: 294-301.

[118] H. Filik, I. Sener, S.D. Cekiç, et al., Spectrophotometric determination of paracetamol in urine with tetrahydroxycalix [4] arena as a coupling reagent and preconcentration with Triton X-114 using cloud point extraction, Chemical and Pharmaceutical Bulletin, 2006, 54(6): 891-896.

[119] H. Zhang, H.K. Choi, Analysis of meloxicam by highperformance liquid chromatography with cloud-point extraction; Analytical and Bioanalytical Chemistry, 2008, 392(5): 947-953.

[120] X.Y. Qin, J. Meng , X.Y. Li, et al., Determination of venlafaxine in human plasma by high performance liquid chromatography using cloud-point extraction and spectrofluorometric detection, Journal of Chromatography B, 2008, 872(1-2): 38-42.

[121] X. Liu, X.H. Chen, Y.Y. Zhang, et al., Determination of Arbidol in rat plasma by HPLC-UV using cloud-point extraction, Journal of Chromatography B, 2007, 856(12): 273-277.

[122] Z. Wei-Jun, W. Liu, J. Chen, et al., Use of cloud point extraction with reprivatizing reagent for the extraction and determination of isoniazid, Journal of Chromatographic Science, 2011, 49(2): 154-158.

[123] W. Zhang, C. Duan, M. Wang, Analysis of seven sulphonamides in milk by cloud point extraction and high performance liquid chromatography, Food Chemistry, 2011, 126(2): 779-785.

[124] H. Ma, J. You, Y. Liu, Cloud-point extraction combined with HPLC of determination of larotaxel in rat plasma: a pharmacokinetic study of liposome formulation, Journal of Separation Science, 2012, 35(12): 1539-1546.

[125] H. Abdollahi, L. Bagheri, Simultaneous spectrophotometric determination of Vitamin $\mathrm{K}_{3}$ and 
1,4-naphthoquinone after cloud point extraction by using genetic algorithm based wavelength selection-partial least squares regression, Anal. Chim. Acta, 2004, 514: 211-218.

[126] B. Tabrizi, A Cloud Point Extraction-Spectrofluorometric Method for Determination of Thiamine in Urine, Bull. Korean Chem. Soc. 2006, 27: 1604-1608.

[127] S.R. Sirimanne, D.G. Patterson, L. Ma, et al, application of cloud-point extraction-reversed-phase highperformance liquid chromatography - a preliminary study of the extraction and quantification of vitamins $A$ and $E$ in human serum and whole blood, J. Chromatogr. B, 1998, 716(1-2): 129-137.

[128] F. Han, R. Yin, X. Shi, et al., Cloud point extractionHPLC method for determination and pharmacokinetic study of flurbiprofen in rat plasma after oral and transdermal administration; Journal of Chromatography $B, 2008,868(1-2)$ : 64-69.

[129] C.C. Wang, M.O. Luconi, A. N. Masi, et al., Determination of terazosin by cloud point extractionfluorimetric combined methodology, Talanta, 2007, 72: 1779.

[130] E. Gniazdowska, N. Korytowska, G. Kłudka, et al., extermination of Antidepressants in Human Plasma by Modified Cloud-Point Extraction Coupled with Mass Spectrometry. Pharmaceuticals. 2020, 13(12): 458-482.

[131] I. Casero, D. Sicilia, S. Rubio, et al., an acid induced phase cloud point separation approach using anionic surfactants for the extraction and preconcentration of organic compounds. Anal. Chem., 1999, 71: 4519-4526.

[132] A.F. Khudhair, S.I. Saeed, A.A Marhoon, A New Spectrophotometric Method to Determine Vitamin B6 in Pharmaceutical Formation Samples Using a Micelle Form, IOP Conf. Series: Journal of Physics: Conf. Series, 2019, 1234: 012087.

[133] S.I. Saeed, A.F. Khudhair, S.K. Abbas, et al., Analysis of Copper (II) in Pharmaceutical Products using Micelle form with the Turbidity Method, Research J. Pharm. and Tech., 2019, 12(5): 2116-2122.

[134] A. Shokrollahi, M. Refahia, development of cloud point extraction-Scanometry, for the preconcentration and determination of colorless species: application for the determination of phenylalanine, Quim. Nova, 2019, 42(1): 36-41.

[135] H.A. Altantawy, W.I. Mortada, E. Abdel-Latif, et al., Cloud Point Extraction of Copper Using 4-(2-Chloroacetamido)- Salicylic Acid as a Complexing Agent, Egypt. J. Chem., 2021, 64(1): 25-32.

[136] S. Ulusoy, M. Akcay, Simultaneous Determination of Vitamins $B_{1}$ and $B_{2}$ in Food Samples by Modified Cloud Point Extraction Method and HPLC-DAD, Food Anal. Method, 2018, 11: 260-269.

[137] R. Heydari, N.S. Elyasi, Ion-pair cloud-point extraction, A new method for the determination of water-soluble vitamins in plasma and urine, J. Sep. Sci., 2014, 37: 2724-
2731.

[138] H.İ. Ulusoy, H. Acıdereli, S. Ulusoy, Development of a New Methodology for Determination of Vitamin B9 at Trace Levels by Ultrasonic-Assisted Cloud Point Extraction Prior to HPLC, Food Anal. Methods, 2007, 10: 799-808.

[139] Z. Fatima, X. Jin, Y. Zou, et al, Recent trends in analytical methods for water-soluble vitamins, Journal of Chromatography A, 2019, 1606: 360245.

[140] S.A. Dhahir, J. Noor, Spectrophotometric Determination and Cloud Point Extraction of Cefixime Drugs in Pure form and Pharmaceutical Preparation, Chemical Science Transactions, 2019, 8(2): 273-288.

[141] M. Safdarian, P. Hashemi, A. Ghiasvand, A fast and simple method for determination of $\beta$-carotene in commercial fruit juice by cloud point extraction-cold column trapping combined with UV-Vis spectrophotometry, Food Chemistry, 2021, 343:128481.

[142] A.C. Ortega, D.C. da Silva, J.V. Visentainer, et al, Determination of Vitamins A and E Exploiting Cloud Point Extraction and Micellar Liquid Chromatography, Analytical Letters, 2011, 44(5): 778-786.

[143] S.A. Dhahir, E.A. Kadhim, R.H.A. AL-Gani, Micro Spectrophotometric Determination and Cloud Point Extraction of Sulphadimidine Sodium in Pure form and Pharmaceutical Drug, Baghdad Science Journal, 2019, 16(2): 332-344.

[144] A. Balati, D. Wagle, K.L. Nash, et al., Heterojunction of $\mathrm{TiO}_{2}$ nanoparticle embedded into ZSM5 to 2D and 3D layered-structures of $\mathrm{MoS}_{2}$ noshes fabricated by pulsed laser ablation and microwave technique in deionized water: structurally enhanced photocatalytic performance, Appl. Nanosci. 2019, 9: 19-32.

[145] A. Balati, S. Tek, K. Nash, et al., Nano architecture of $\mathrm{TiO}_{2}$ microspheres with expanded lattice interlayers and its heterojunction to the laser modified black $\mathrm{TiO}_{2}$ using pulsed laser ablation in liquid with improved photocatalytic performance under visible light irradiation, Journal of Colloid and Interface Science, 2019, 541: 234248.

[146] A. Balati, A. Matta, K. Nash, et al., Heterojunction of vertically aligned $\mathrm{MoS}_{2}$ layers to Hydrogenated Black $\mathrm{TiO}_{2}$ and Rutile Based Inorganic Hollow Microspheres for the highly enhanced visible light arsenic photo oxidation, Composites Part B: Engineering, 2020, 185: 107785.

Copyright $₫$ Ebaa Adnan Azooz, Rana Kadhim Ridha, and Hawraa Ali Abdulridha. This is an open-access article distributed under the terms of the Creative Commons Attribution License, which permits unrestricted use, distribution, and reproduction in any medium, provided the original author and source are credited. 